\title{
An elderly woman with an indurated plaque on the right Buttock
}

\author{
Mariem Rekik ${ }^{1}$, kouki chaima ${ }^{1}$, Nadine Kammoun ${ }^{1}$, Khadija Sellami ${ }^{2}$, mariem Triki ${ }^{3}$, emna \\ bahloul $^{1}$, Sonia Boudaya ${ }^{1}$, mariem Amouri ${ }^{1}$, Tahya Boudawara ${ }^{3}$, and Hamida Turki ${ }^{1}$ \\ ${ }^{1}$ Hedi Chaker Hospital \\ ${ }^{2}$ Hopital Hedi Chaker \\ ${ }^{3}$ Habib Bourguiba Hospital
}

February 25, 2022

\begin{abstract}
Malignant melanoma presenting as an inflammatory skin metastasis has been described but is an exceedingly rare phenomenon. We report a case of inflammatory metastasis of cutaneous melanoma (CM)
\end{abstract}

\section{Indurate plaque in an elderly woman}

A 76-year-old woman was admitted for 1-month evolving painful indurated plaques of the right buttock without fever. On physical examination, the patient had a $10 \mathrm{~cm}$ plaque with multiple erythematous nodules (Figure 1). CT-scan showed multiple tumor processes in the lung, stomach with nodular tissue thickening of the buttock. Biopsy showed subcutaneous infiltration by a malignant tumor whose morphology and immunohistochemical staining are matching with cutaneous melanoma (CM). (Figure 2)

The patient reported a history of surgical excision of a CM located on the breast two years ago.

Diagnosis of melanoma erysipeloid (ME) was made. Because of the advanced tumor stage and the limited treatment options in our country, palliative attitude was recommended.

Malignant melanoma presenting as an inflammatory skin metastasis is an exceedingly rare phenomenon. ${ }^{1}$ To our knowledge there are only 11 reported cases of ME. ${ }^{2}$

In our patient, clinical aspect of the lesion, absence of fever and negative biological findings were suggestive of ME. Differential diagnosis between erysipelas and ME may be difficult. Histology remains the main key for diagnosis. ${ }^{2}$

While cases of ME have been located around the primary tumor, in the skin overlying regional lymph node metastases ${ }^{2}$, our patient's location is quite unusual.

\section{References:}

1. Plaza JA, Torres-Cabala C, Evans H, Diwan HA, Suster S, Prieto VG. Cutaneous metastases of malignant melanoma: a clinicopathologic study of 192 cases with emphasis on the morphologic spectrum. Am J Dermatopathol. avr 2010;32(2):129-36.

2. Hillen U, Willers C, Goos M. Melanoma erysipeloides: successful treatment by chemoimmunotherapy: CORRESPONDENCE. British Journal of Dermatology. oct 2000;143(4):904-6.

Figures legend:

Figure 1: Erythematous and infiltrated plaque of the right buttock mesuring $10 \mathrm{~cm}$ 
Figure 2: Metastatic melanoma to the right butttock:

A) Sheets of atypical cells in the hypodermis (arrow) (HEx50),

B) At high magnification, the tumor cells, invading the fat connective tissue, are round with eosinophilic cytoplasm and hyperchromatic nuclei (HEx200),

C) The tumor cells are positives for pS100 (x400).

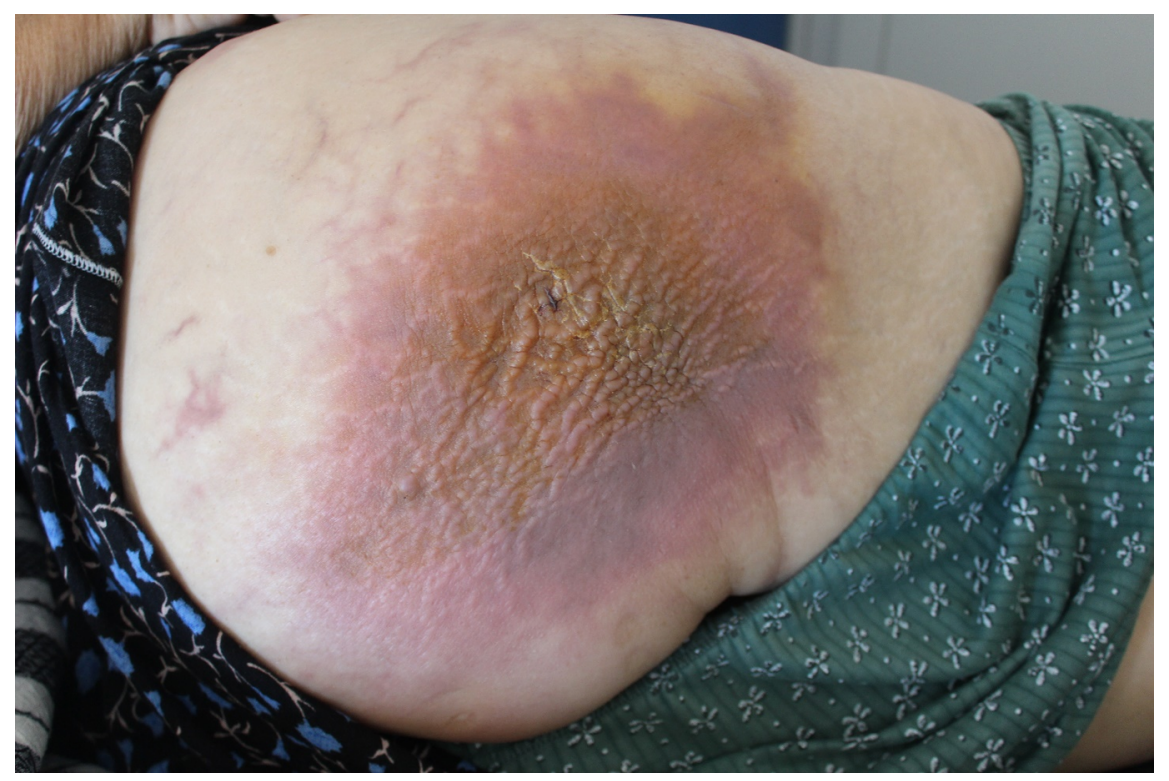

Figure 1
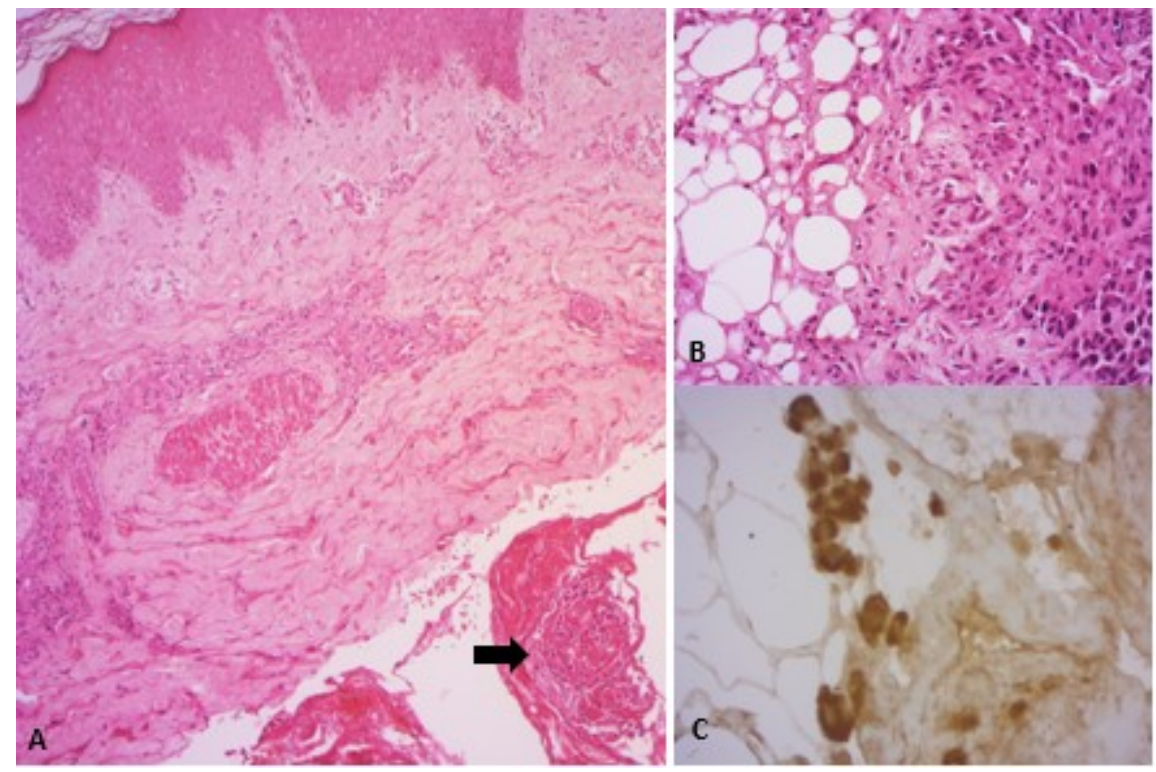

Figure 2

\section{Medical key message}


Infiammatory carcinoma or carcinoma erysipeloides is a well-recognized, although uncommon, cutaneous manifestation of metastatic malignancy, accounting for $4 \%$ of skin metastases. It is most frequently associated with carcinoma of the breast, but has been reported with other primary tumours, including lung and colon.

Malignant melanoma presenting as an inflammatory skin metastasis has been described but is an exceedingly rare phenomenon. We report a case of inflammatory metastasis of cutaneous melanoma (CM). 